\title{
A Comparative Photophysical Study of Structural Modifications of Thioflavin T- Inspired Fluorophores
}

Lisa-Maria Needham ${ }^{a}$, Judith Weber ${ }^{a, b, c}$, Colin M. Pearson ${ }^{d}$, Dung T. Do ${ }^{d}$, Felix Gorka ${ }^{a}$, Guanpeng Lyu ${ }^{a}$, Sarah E. Bohndiek ${ }^{b}$, Thomas N. Snaddon ${ }^{d *}$ and Steven F. Lee ${ }^{a *}$

\author{
Author Information \\ * denotes joint corresponding authors \\ a Department of Chemistry, University of Cambridge, Cambridge, CB2 1EW, UK \\ ${ }^{b}$ Department of Physics, University of Cambridge, Cambridge, CB3 OHE, UK \\ ${ }^{c}$ Cancer Research UK Cambridge Institute, University of Cambridge, Cambridge, CB2 ORE, \\ UK \\ d Department of Chemistry, Indiana University, Bloomington, Indiana, 47405, USA
}

\begin{abstract}
The benzothiazolium salt, Thioflavin T (ThT), has been widely adopted as the 'gold-standard' fluorescent reporter of amyloid in vitro. Its properties as a molecular rotor result in a largescale ( 1000-fold) fluorescence turn-on upon binding to $\beta$-sheets in amyloidogenic proteins. However, the complex photophysics of ThT combined with the intricate and varied nature of the amyloid binding motif means these interactions are poorly understood. To study this important class of fluorophore, we present a detailed photophysical characterisation and comparison of a novel library of twelve ThT-inspired fluorescent probes for amyloid protein (PAPs), where both the charge and donor capacity of the heterocyclic and aminobenzene components have been interrogated, respectively. This enables direct photophysical juxtaposition of two structural groups; Class 1 the neutral 'PAP' and Class 2 the charged 'mPAP' fluorophores. We quantify binding and optical properties at both the bulk and singleaggregate levels with some derivatives showing higher aggregate affinity and brightness than ThT. Finally, we demonstrate their abilities to perform super-resolution imaging of $\alpha$ synuclein fibrils with localisation precisions of $\sim 16 \mathrm{~nm}$. The properties of the derivatives provide new insights into the relationship between chemical structure and function of benzothiazole probes.
\end{abstract}




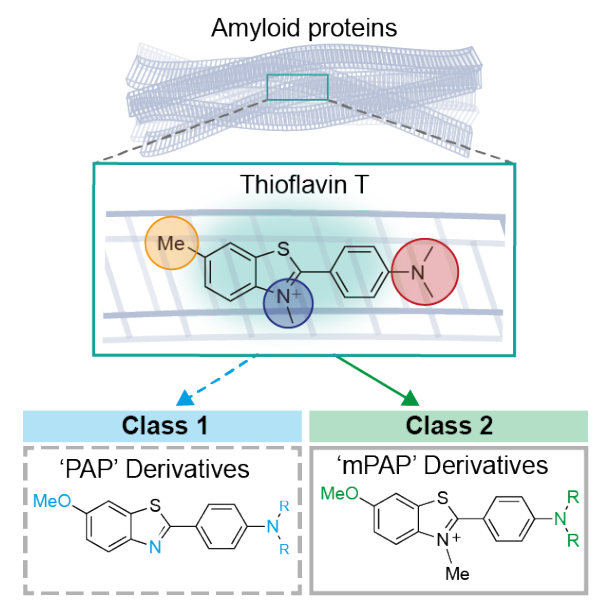

\section{Keywords}

Fluorophores • Photophysics • Amyloid proteins • Fluorescence imaging • Super-resolution microscopy $•$ Neurodegeneration

Protein misfolding, aggregation and subsequent intra and extra-cellular accumulation of insoluble proteins is the pathological hallmark of many neurodegenerative diseases (Figure $1 \mathrm{~A}) .^{1-4}$ The process of in vitro amyloid formation is commonly studied by employing extrinsic fluorophores, including, but not limited to, compounds such a Congo red, ${ }^{5}$ multimeric thiophenes, ${ }^{6}$ 8-anilino-1-napththalenesulfonic acid (ANS), ${ }^{7}$ Nile red $^{8}$ and $\beta$-sheet sensitive aryl-benzothiazoles. ${ }^{9}$ Among those is the $\mathrm{N}$-methyl benzothiazolium cation, Thioflavin $\mathrm{T}$ (ThT), that has become the gold-standard fluorophore to monitor the kinetics of in vitro amyloid formation. ${ }^{10-19}$ One key structural feature common between different amyloid fibrils is the layers of cross- $\beta$ sheets, which present an ordered array of side chains towards the surface. These side chains emanate from a channel-like motif running parallel to the long fibril axis. ThT is generally understood to bind transiently and in a regular arrangement ${ }^{20}$ to these channels with a $\mu \mathrm{M}$ affinity. ${ }^{21-23}$ The binding results in a fluorescence turn-on response of ThT which has been exploited to observe the formation of amyloid aggregates with bulk fluorescence spectroscopy. Additionally, ThT-based fluorescence imaging experiments visualise the heterogeneity of species produced in the aggregation process. ${ }^{9,20,24-26}$

ThT has many favourable photophysical properties that can be effectively explained by the molecular rotor model. ${ }^{27-33}$ In low viscosity solvents a twisted intramolecular charge transfer (TICT) state is formed as a result of photo-induced charge redistribution coupled with a dihedral twist about the $\mathrm{C}-\mathrm{C} \sigma$-bond between the benzothiazole and dimethylaniline moieties. The energy gap between the TICT and ground state is such that relaxation is nonradiative. Upon $\beta$-sheet binding, the rotation is suppressed and fluorescence emission from 
the locally excited (LE) state dominates. This excited state behaviour results in large Stokes shifts, low fluorescence quantum yield $\left(\Phi_{\mathrm{Fl}}\right)$ in solution and fluorescence turn-on upon amyloid incorporation. In combination these properties provide the high contrast required to image single aggregates. Despite these advantages, ThT fluorescence in the context of amyloid aggregation is poorly understood. The optical and binding properties of some derivatives of ThT have been studied previously, including the cationic ICT dyes ${ }^{34}$ and neutral $\mathrm{BTA}^{35-37}$ and $2 \mathrm{Me}-\mathrm{DABT}{ }^{38,39}$ Pittsburgh compound $\mathrm{B}(\mathrm{PiB})$, a structurally similar but neutral benzothiazole, has an affinity for amyloid approximately 300 -fold greater than $\mathrm{ThT},{ }^{35}$ due to the increased lipophilicity which results in stronger interactions with hydrophobic residues. ${ }^{40}$ As a consequence, $\mathrm{PiB}$ does not undergo the enhancement of $\Phi_{\mathrm{FI}}$ upon amyloid binding, ${ }^{41}$ rendering it a poor fluorescence reporter of amyloid. However, the higher lipophilicity and greater affinity for amyloid protein of PiB led to its development as a PET probe for in vivo detection. ${ }^{42}$

Despite sustained investigation, there is little understanding of the de facto structural features required for high-performance optical function. Thus, in order to enable the rational design of more effective, selective and sensitive probes that can inform our understanding of the complex amyloid aggregation process, there is a critical need to delineate the impact that structural modifications to benzothiazole and benzothiazolium amyloid dyes have on optical function (Figure 1A). Herein this work describes the synthesis and photophysical characterisation and comparison of a spectrochemical series of ThT-inspired dyes. In order to explore the optical effects of $N$ electron donor capacity and increased steric demand of the phenyl substituent, the dimethyl amino moiety was substituted for different arylamine donor units. Furthermore, the imine/iminium acceptor properties of the benzothiazole $N(N-5)$ were interrogated by both removing and preserving the $N-5$ methylation. Across all derivatives, the aromatic methyl group was substituted for a methoxy, providing both a synthetic handle for potential functionalisation and increased electron density on the chromophore. Given that the amine donor substituent is known to influence the properties of benzothiazolium amyloid dyes so profoundly, we codified these molecules into two subclasses; Class 1 comprise neutral benzothiazole (PAP), and Class 2 the charged benzothiazolium (mPAP) congeners (Figure 1B). This investigation of structure-activity relationship explores and evaluates the optical effect of $N$ donor capacity as a function of vastly different benzothiazole/benzothiazolium acceptor properties between these two classes. Due to its performance in the field of amyloid imaging, several bulk and singleaggregate level photophysical properties have been quantified and compared to ThT. 

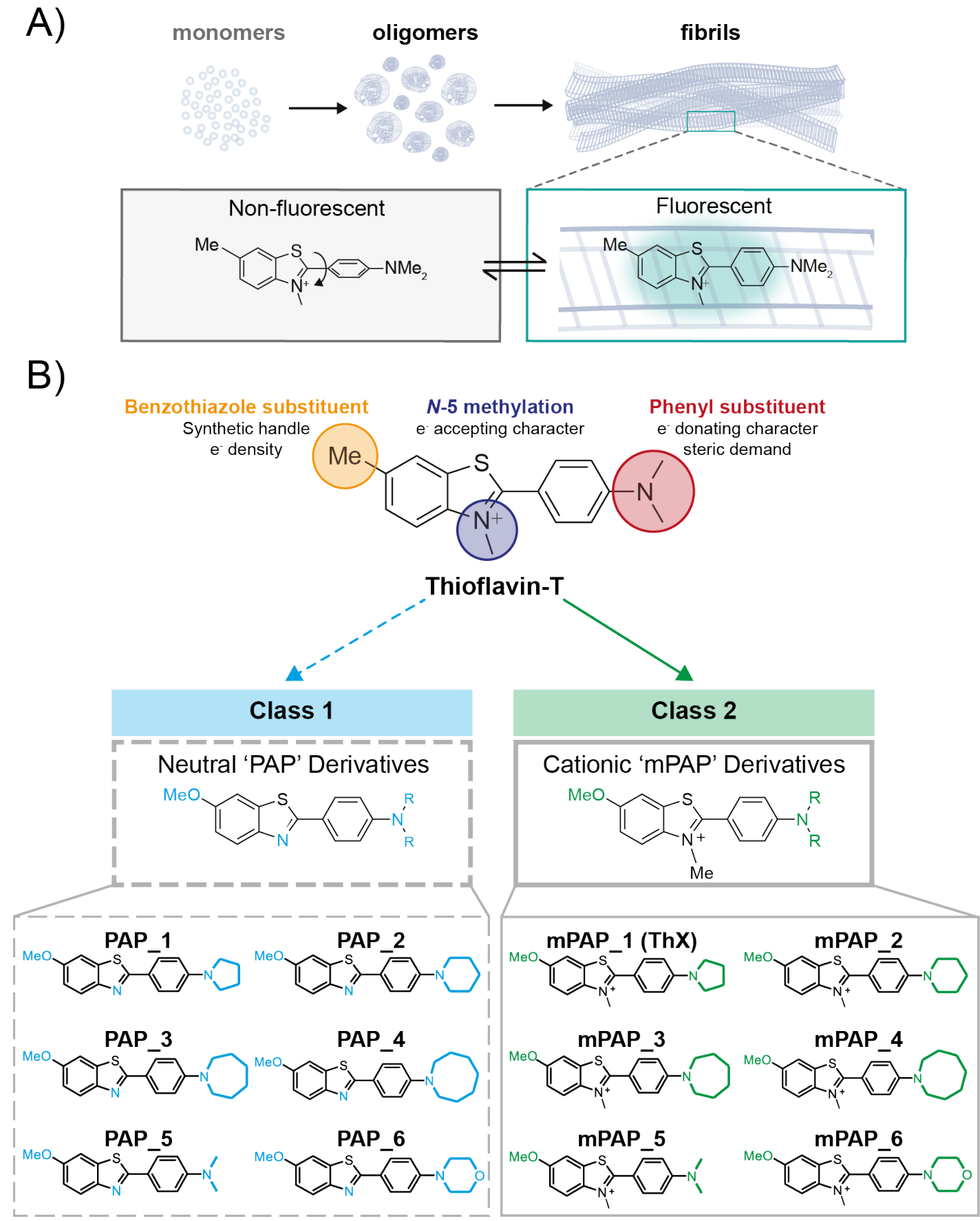

Figure 1. A) Simplified schematic of amyloid aggregation and ThT binding. The fluorescence excited state of ThT is quenched in low viscosity media as it acts a molecular rotor. This rotation is restricted upon docking to $\beta$-sheet containing amyloid aggregates resulting in an increase of $\Phi_{\mathrm{Fl}}$ of several orders of magnitude. B) The two classes of novel ThT-inspired analogues characterised in this work; Class 1: the neutral PAP derivatives and their $Z=+1$, benzothiazole $N$-methylated congeners, Class 2: the mPAP derivatives.

In order to fully interrogate those structural features relevant to fluorescence activity we developed a conserved synthesis strategy, which hinged on the diversification of readily accessible bromide $\mathbf{X}$ via Pd-catalysed Buchwald-Hartwig $\mathrm{C}-\mathrm{N}$ bond formation. ${ }^{43}$ This enabled straightforward access to neutral 'PAP' analogues, which were then subjected to 
selective $\mathrm{N}$-methylation of the benzothiazole sub-unit in order to prepare the structurally analogous cationic 'mPAP' analogues.

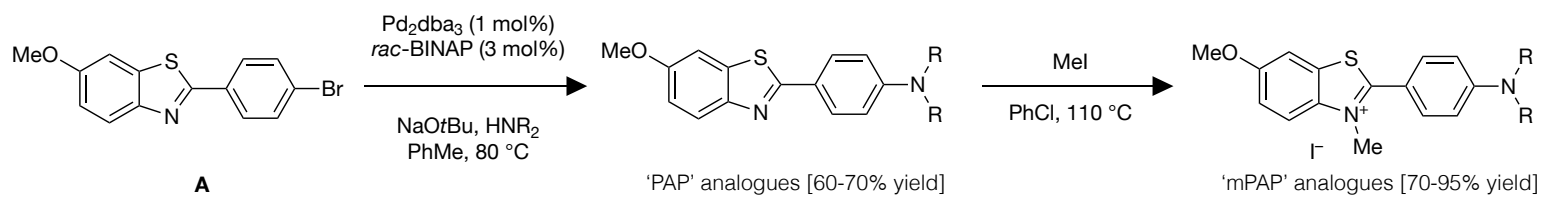

Scheme 1. Preparation of 'PAP' and 'mPAP' ThT analogues via a Pd-catalyzed amination and benzothiazole $N$-methylation.

Bulk absorption and emission (Figure 2, Figure S1) and excitation (Figure S2) of ThT, PAP and mPAP dyes were measured in phosphate buffered saline (PBS) and in the presence of recombinant $\alpha$-Synuclein ( $\alpha$ Syn) aggregates (>96 hours). $\alpha$ Syn is presynaptic nerve terminal protein and the major component of Lewy bodies, the pathological hallmark of Parkinson's disease. ${ }^{2}$ This allowed the direct comparison of the optical properties of the 'free' dyes in a low viscosity, physiologically relevant environment and the 'confined' dyes bound to amyloid. From these data we extracted several photophysical quantities summarised in Tables 1-4 including wavelengths of maximum absorption $\left(\lambda_{\mathrm{abs}}\right)$, excitation $\left(\lambda_{\mathrm{ex}}\right)$ and fluorescence emission $\left(\lambda_{\mathrm{em}}\right)$; Stokes shift $\left(\lambda_{\mathrm{em}}-\lambda_{\mathrm{abs}}\right)$; molar extinction coefficient $(\varepsilon)$; fluorescence quantum yield $\left(\Phi_{\mathrm{Fl}}\right)$; fluorescence lifetime $\left(\mathrm{T}_{\mathrm{fl}}\right)$ and brightness $\left(\mathrm{B}\right.$, equal to $\left.\varepsilon \times \Phi_{\mathrm{Fl}}\right)$. Tables 1 and 2 state the properties of the dyes in PBS and Tables 3 and 4 show the properties of the dyes in the presence of late-stage recombinant aggregates of aSyn. In addition, the dissociation constants $\left(K_{D}\right)$ of the ThT, PAP and mPAP derivatives to aSyn aggregates were measured using surface plasmon resonance (SPR) spectroscopy. Symbols of the aforementioned properties are denoted by subscript ' 1 ' for the dyes in PBS and ' 2 ' for the dyes with aSyn aggregates. 


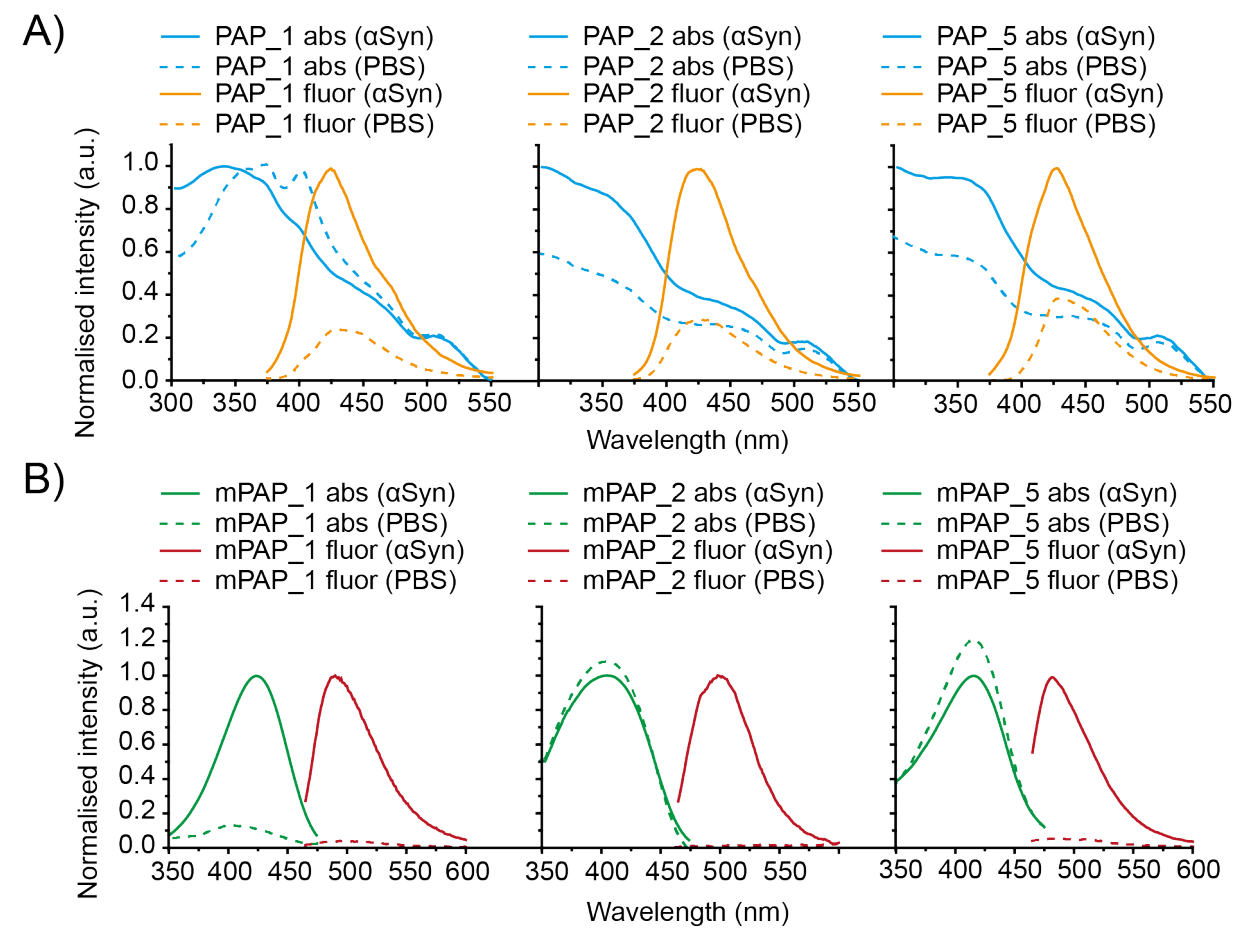

Figure 2. Bulk UV-vis absorption and emission spectra of $10 \mu \mathrm{M}$ A) PAP derivatives (PAP_1, PAP_2 and PAP_5) and B) mPAP derivatives (mPAP_1, mPAP_2, mPAP_5) in PBS and with $2 \mu \mathrm{M}$ recombinant aSyn aggregates ( $>96$ hours). The spectra have been independently normalised relative to the maximum intensity of the dye in the presence of aSyn aggregates.

The aromatic methoxy functionality is a common structural feature across the PAP and mPAP derivatives but differs from the methyl of ThT. The MPAP_5 derivative possesses only this substitution relative to the ThT structure to enable the key characterisation of the optical effect of this alteration. It was promising that MPAP_5 possessed nearly identical $\lambda_{\text {abs } 1}$ and $\lambda_{\mathrm{em} 1}$ to ThT (414 $\mathrm{nm}$ and $484 \mathrm{~nm}$ respectively). However, it showed clear differences in $\varepsilon_{1}, \Phi_{\mathrm{F} 11}$ and $\mathrm{B}_{1}$. $\varepsilon_{1}$ was $2.5 \times$ lower than ThT suggesting the methoxy substituent negatively influences the oscillator strength. ${ }^{37,44}$ The measured $\Phi_{\mathrm{F} 11}$ of mPAP_5 was $7 \times$ higher than ThT ( 0.007 and 0.001 respectively), this lead to $55 \%$ overall increase in $B_{1}$ of mPAP_5 relative to ThT. Overall this suggests that the increased electron density introduced by the methoxy substituent does not induce a chromatic shift in the optical properties but does affect the efficiency of photon absorption and emission. 
Table 1. Table of photophysical properties of the PAP dyes and ThT obtained from bulk UV-vis absorption, excitation and fluorescence measurements of the dyes free in PBS (denoted by subscript 1). Determined properties include wavelengths of maximum absorption $\left(\lambda_{\mathrm{abs} 1}\right)$ excitation $\left(\lambda_{\mathrm{ex} 1}\right)$ and fluorescence emission $\left(\lambda_{\mathrm{em} 1}\right)$; Stokes shift $\left(\lambda_{\mathrm{em} 1}-\lambda_{\mathrm{abs} 1}\right)$; molar extinction coefficient $\left(\varepsilon_{1}\right)$; fluorescence quantum yield $\left(\Phi_{\mathrm{Fl1} 1}\right)$; fluorescence lifetime $\left(\mathrm{T}_{\mathrm{fl} 11}\right)$ and brightness $\left(\mathrm{B}_{1}\right.$, equal to $\left.\varepsilon_{1} \times \Phi_{\mathrm{Fl1}}\right)$. IRF defines the instrument response function of the fluorescence lifetime instrument.

\begin{tabular}{|c|c|c|c|c|c|c|c|c|c|c|}
\hline Dye & $\mathbf{R}$ group & $\begin{array}{l}\lambda_{\text {abs1 }} \\
(\mathrm{nm})\end{array}$ & $\begin{array}{l}\lambda_{\mathrm{ex} 1} \\
(\mathrm{~nm})\end{array}$ & $\begin{array}{l}\lambda_{\mathrm{em} 1} \\
(\mathrm{~nm})\end{array}$ & $\begin{array}{c}\lambda_{\text {em1 } 1-\lambda_{\text {abs1 }}} \\
(\mathrm{nm})\end{array}$ & $\begin{array}{c}\varepsilon_{1} \\
\left(\mathrm{M}^{-1} \mathrm{~cm}^{-1}\right) \\
/ 10^{3}\end{array}$ & $\Phi_{\mathrm{F} 11}$ & $\begin{array}{l}\text { Tf11 } \\
\text { (ns) }\end{array}$ & $\begin{array}{c}\mathrm{B}_{1} \\
\left(\mathrm{M}^{-1} \mathrm{~cm}^{-1}\right)\end{array}$ & $\frac{\mathbf{B}_{1}^{\text {PAP }}}{\mathbf{B}_{1}^{\text {ThT }}}$ \\
\hline ThT & & 413 & 408 & 488 & 75 & 36.00 & 0.001 & $<$ IRF & 36.0 & 1.00 \\
\hline PAP_1 & & 370 & 333 & 429 & 59 & 3.02 & 0.007 & 1.26 & 20.6 & 0.57 \\
\hline PAP_2 & & 328 & 330 & 433 & 105 & 1.47 & 0.023 & 0.55 & 33.8 & 0.94 \\
\hline PAP_3 & & 371 & 327 & 445 & 74 & 1.32 & 0.031 & --- & 40.9 & 1.14 \\
\hline PAP_4 & & 300 & 335 & 441 & 141 & 1.28 & 0.035 & 0.87 & 44.9 & 1.25 \\
\hline PAP_5 & & 301 & 343 & 432 & 131 & 1.02 & 0.055 & 1.26 & 56.0 & 1.55 \\
\hline PAP_6 & s' & 325 & 334 & 439 & 114 & 0.94 & 0.039 & 1.02 & 36.6 & 1.02 \\
\hline
\end{tabular}

In PBS the PAP derivatives all absorbed in the ultraviolet region between $300-371 \mathrm{~nm}$, hypsochromically shifted relative to the $\lambda_{\text {abs }}$ of ThT, this was expected due to reduced conjugation. Under these conditions, the PAP derivatives were weak photon absorbers and showed complex absorption spectra. At $\lambda_{\text {abs } 1}$ all $\varepsilon_{1}$ values were $<3000 \mathrm{M}^{-1} \mathrm{~cm}^{-1}$. Poor solubility in aqueous buffer and subsequent aggregation and possible precipitation of PAP was the most likely cause of the low measured $\varepsilon_{1}$ and absorption spectra features. This was evidenced by measurement of PAP absorption spectra in less polar ethanol (EtOH). The measured maximum absorbance of PAP in $\mathrm{EtOH}$ was between 2.0 and 107.2-fold greater than the same concentration (calculated by mass) in PBS (Figure S3A). This suggests that the dissolved PAP concentration in PBS was substantially lower than calculated. Despite this, it was important to quantify the optical behaviour in aqueous solution as this most closely represents the environment in which the dyes would be applied. A reduction in oscillator strength may result from the absence of the positive charge and thus contribute to the lower $\varepsilon_{1}$ compared to ThT. The long and short wavelength peaks seen in the absorption 
spectra of the PAP dyes may result from protonation of $N-5$, forming a mixture of neutral and cationic molecules as previously described. ${ }^{45}$

The $\Phi_{\mathrm{F} 11}$ of the PAP derivatives were $\sim 10 \times$ greater than ThT. This can be partially explained by the existence of a higher energy barrier to rotation about the $\mathrm{C}-\mathrm{C} \sigma$ bond between phenyl and benzothiazolium rings, ${ }^{46}$ which increases the probability that photo-excited PAP dyes will occupy a LE state rather than a TICT state in low viscosity media. The total integrated emission intensity (I) of the PAP dyes increased substantially (24.0-282.5 $\times$ ) in EtOH relative to PBS (Figure S3B). The ratio of the increase in integrated emission intensity $\left(\frac{\mathrm{I}_{\mathrm{EO} O H}}{\mathrm{IPBS}}\right)$ to absorbance $\left(\frac{A_{\mathrm{E}_{\mathrm{EOH}}}}{\mathrm{A}_{\mathrm{PBS}}}\right)$ was greater than unity in all cases (2.6-16.7), supporting the attribution of low measured $\Phi_{\mathrm{F} 11}$ values $(<0.1)$ to excited-state quenching induced by dye-dye hydrophobic interactions. $^{45}$

Table 2. Table of photophysical properties of the mPAP dyes and ThT obtained from bulk UV-vis absorption, excitation and fluorescence measurements of the dyes free in PBS buffer (denoted by subscript 1). Determined properties include wavelengths of maximum absorption $\left(\lambda_{\mathrm{abs} 1}\right)$, excitation $\left(\lambda_{\mathrm{ex} 1}\right)$ and fluorescence emission $\left(\lambda_{\mathrm{em} 1}\right)$; Stokes shift $\left(\lambda_{\mathrm{em} 1}-\lambda_{\mathrm{abs} 1}\right)$; molar extinction coefficient $\left(\varepsilon_{1}\right)$; fluorescence quantum yield $\left(\Phi_{\mathrm{F} 11}\right)$; fluorescence lifetime ( $\left.\mathrm{T}_{\mathrm{fl} 1}\right)$ and brightness $\left(\mathrm{B}_{1}\right.$, equal to $\left.\varepsilon_{1} \times \Phi_{\mathrm{Fl1}}\right)$. IRF defines the instrument response function of the fluorescence lifetime instrument.

\begin{tabular}{|c|c|c|c|c|c|c|c|c|c|c|}
\hline Dye & $\mathbf{R}$ group & $\begin{array}{l}\lambda_{\text {abs1 }} \\
(\mathrm{nm})\end{array}$ & $\begin{array}{l}\lambda_{\text {ex1 }} \\
(\mathrm{nm})\end{array}$ & $\begin{array}{l}\lambda_{\mathrm{em} 1} \\
(\mathrm{~nm})\end{array}$ & $\begin{array}{c}\lambda_{\mathrm{em} 1}-\lambda_{\mathrm{abs} 1} \\
(\mathrm{~nm})\end{array}$ & $\begin{array}{c}\varepsilon_{1} \\
\left(\mathrm{M}^{-1} \mathrm{~cm}^{-1}\right) \\
/ 10^{3}\end{array}$ & $\Phi_{\mathrm{F} 11}$ & $\begin{array}{l}\text { Tf11 } \\
\text { (ns) }\end{array}$ & $\begin{array}{c}\mathrm{B}_{1} \\
\left(\mathrm{M}^{-1} \mathrm{~cm}^{-1}\right)\end{array}$ & $\frac{\mathrm{B}_{1}^{\mathrm{mPAP}}}{\mathrm{B}_{1}^{\mathrm{ThT}}}$ \\
\hline ThT & & 413 & 408 & 488 & 75 & 36.00 & 0.001 & $<\mathrm{IRF}$ & 39.60 & 1.00 \\
\hline mPAP_1 & & 420 & 420 & 494 & 74 & 31.15 & 0.005 & $<\mathrm{IRF}$ & 165.08 & 8.65 \\
\hline mPAP_2 & & 404 & 369 & 496 & 92 & 16.04 & 0.006 & $<\mathrm{IRF}$ & 89.82 & 1.11 \\
\hline mPAP_3 & & 423 & 329 & 500 & 77 & 27.41 & 0.007 & --- & 178.13 & 5.71 \\
\hline mPAP_4 & & 423 & $335 / 424$ & 498 & 75 & 20.82 & 0.017 & $<\mathrm{IRF}$ & 353.99 & 7.23 \\
\hline mPAP_5 & & 414 & 411 & 484 & 70 & 14.18 & 0.007 & $<\mathrm{IRF}$ & 103.51 & 1.97 \\
\hline mPAP_6 & $-\mathrm{N}$ & 380 & 375 & 513 & 133 & 17.22 & 0.006 & $<\mathrm{RRF}$ & 94.71 & 3.59 \\
\hline
\end{tabular}


The most relevant photophysical quantity for the fluorescence detection of amyloid is $\mathrm{B}_{1}$. It is desirable for $\mathrm{B}_{1}$ to be below the detection capabilities of the detector as any signal produced from unbound dyes will contribute to the background and reduce contrast. Despite the higher $\Phi_{\mathrm{Fl}}$ compared to $\mathrm{ThT}$, the poor $\varepsilon_{1}$ results in comparable $\mathrm{B}_{1}$ in PBS and therefore a low fluorescence background contribution.

The mPAP dyes had $\lambda_{\text {abs } 1}$ bathochromically shifted from their PAP partners, a consequence of the increased conjugation introduced by methylation of $N-5$. Large Stokes shifts $(>70 \mathrm{~nm})$ were observed with mPAP dyes, similar to ThT. This is consistent with geometric relaxation of the dyes in the photo-excited state. ${ }^{24,47}$ Like mPAP_5, $\varepsilon_{1}, \Phi_{\mathrm{F} 11}$ and $B_{1}$ of all the MPAP derivatives differed to ThT. $\varepsilon_{1}$ was lower in all cases, a potential consequence of reduced oscillator strength caused by the methoxy substituent. Contrary to the PAP derivatives, the absorbance of the mPAP dyes did not change significantly in $\mathrm{EtOH}(0.9-2.1 \times)$ suggesting that incomplete dissolution of the dyes was minimal (Figure S3A). The $\Phi_{\mathrm{F} 11}$ of mPAP dyes were at least $5 \times$ greater than ThT and therefore had a higher background fluorescence intensity $\left(B_{1}\right)$. This further suggests that the additional electron density of the methoxy substituent reduces the probability of non-radiative decay from the photo-excited state. $I_{E t O H}$

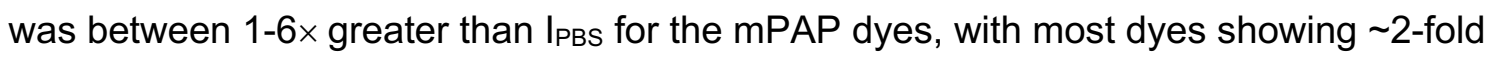
higher intensities that may result from the higher viscosity of $\mathrm{EtOH}$ compared to water. ${ }^{45}$

Comparing the different structural modifications made on the aryl nitrogen, revealed a positive relationship between $\Phi_{\mathrm{Fl1}}$ and ring size of the phenyl $\mathrm{N}$-heterocycle substituent for both PAP and mPAP derivatives (Figure S4). This suggests that TICT can be impeded sterically, and furthermore that molecular rotor behaviour may contribute to the emission properties of the PAP dyes. Despite this, ThT and mPAP derivatives had excited state lifetimes faster than the instrument response function (IRF, Figure S5A,B) in PBS, characteristic of molecular rotors. ${ }^{48}$ The PAP dyes showed longer lifetimes ( 1 ns, Figure $\mathrm{S} 5 \mathrm{C})$, in accordance with their greater $\Phi_{\mathrm{F} 11}$ and further supporting their minimal rotor behaviour. $^{45}$

All the dyes displayed altered photophysical properties in response to amyloid incorporation. It is important to note that the amyloid bound bulk photophysical quantities are not absolute values as the sample contained an unknown ratio of bound and unbound dye molecules. However, the experimental conditions, such as aggregation samples and protein concentrations, were carefully maintained across all dyes. Therefore, the determined 
parameters are able to be compared between the different probes and can therefore be used to inform on the impacts of modifications to the probe structure.

Table 3. Table of photophysical and binding properties of the PAP dyes and ThT obtained from bulk UV-vis absorption, excitation, fluorescence and SPR measurements of the dyes in the presence of $2 \mu \mathrm{M}$ aSyn aggregates (denoted by subscript 2). Determined properties include wavelengths of maximum absorption $\left(\lambda_{\mathrm{abs} 2}\right)$, excitation $\left(\lambda_{\mathrm{ex} 2}\right)$ and fluorescence emission $\left(\lambda_{\mathrm{em} 2}\right)$; Stokes shift $\left(\lambda_{\mathrm{em} 2}-\lambda_{\mathrm{abs} 2}\right)$; molar extinction coefficient $\left(\varepsilon_{2}\right)$; fluorescence quantum yield $\left(\Phi_{\mathrm{Fl} 2}\right)$; fluorescence lifetime $\left(\mathrm{T}_{\mathrm{fl} 2}\right)$; brightness $\left(\mathrm{B}_{2}\right.$, equal to $\left.\varepsilon_{2} \times \Phi_{\mathrm{F} \mid 2}\right)$ and dissociation constant $\left(\mathrm{K}_{\mathrm{D}}\right)$.

\begin{tabular}{|c|c|c|c|c|c|c|c|c|c|c|c|}
\hline Dye & $\mathbf{R}$ group & $\begin{array}{l}\lambda_{\text {abs2 }} \\
(\mathrm{nm})\end{array}$ & $\begin{array}{l}\lambda_{\mathrm{ex} 1} \\
(\mathrm{~nm})\end{array}$ & $\begin{array}{l}\lambda_{\mathrm{em} 2} \\
(\mathrm{~nm})\end{array}$ & $\begin{array}{l}\lambda_{\text {em2- }} \\
\lambda_{\text {abs2 }} \\
(n m)\end{array}$ & $\begin{array}{c}\varepsilon_{2} \\
\left(\mathrm{M}^{-1} \mathrm{~cm}^{-1}\right) \\
/ 10^{3}\end{array}$ & $\Phi_{\mathrm{F} 12}$ & $\begin{array}{l}T_{\mathrm{fl} 12} \\
\text { (ns) }\end{array}$ & $\begin{array}{c}\mathrm{B}_{2} \\
\left(\mathrm{M}^{-1} \mathrm{~cm}^{-1}\right)\end{array}$ & $\frac{B_{2}^{\text {PAP }}}{B_{2}^{\text {ThT }}}$ & $\begin{array}{l}\mathrm{K}_{\mathrm{D}} \\
(\mu \mathrm{M})\end{array}$ \\
\hline ThT & & 414 & 447 & 483 & 69 & 29.52 & 0.24 & 0.14 & 7173.4 & 1.00 & 79.4 \\
\hline PAP_1 & & 367 & 336 & 425 & 58 & 4.84 & 0.01 & 0.24 & 53.3 & 0.01 & 0.10 \\
\hline PAP_2 & & 330 & 338 & 425 & 95 & 2.79 & 0.08 & 0.36 & 227.8 & 0.03 & 0.22 \\
\hline PAP_3 & & 373 & 324 & 427 & 54 & 3.26 & 0.04 & --- & 140.1 & 0.02 & 0.36 \\
\hline PAP_4 & & 374 & 337 & 431 & 57 & 4.25 & 0.07 & 0.35 & 282.2 & 0.04 & 0.10 \\
\hline PAP_5 & & 305 & 353 & 429 & 124 & 2.06 & 0.08 & 0.53 & 172.1 & 0.02 & 0.33 \\
\hline PAP_6 & & 320 & 334 & 427 & 107 & 1.02 & 0.04 & 0.43 & 42.0 & 0.01 & 0.18 \\
\hline
\end{tabular}

ThT and, in all cases, the PAP and mPAP derivatives showed small reductions in Stokes shift upon aSyn incorporation resulting from a hypsochromic shift in $\lambda_{\mathrm{em}}$. This observation may be indicative of inhibition of molecular rotation during amyloid binding and is in agreement with current models that describe the origins of $\Phi_{\mathrm{Fl}}$ increase of ThT upon amyloid incorporation. ${ }^{23}$ mPAP_1 (ThX), exhibited several favourable properties upon binding to aSyn aggregates which have previously been described in detail. ${ }^{49}$

The $\mathrm{T}_{\mathrm{F} 22}$ of ThT (Figure S6A), mPAP (Figure S6B) and PAP (Figure S6C) dyes were altered in response to aSyn aggregate binding. The $\mathrm{T}_{\mathrm{F} 12}$ of ThT and the MPAP dyes increased from below the IRF to 0.06-0.36 ns likely resulting from suppression of the TICT state and subsequent non-radiative decay. Interestingly, the PAP derivatives exhibited opposing behaviour. Despite increasing in $\Phi_{\mathrm{Fl}}$ in response to aSyn aggregate binding, $\mathrm{T}_{\mathrm{Fl}}$ decreased at most, in the case of PAP_1, by a factor of 5 . In combination these data suggest there are 
multiple variables governing the photo-excited state behaviour and therefore optical responses of these dyes upon amyloid incorporation. ${ }^{22}$

$\frac{B_{2}}{B_{1}}$ or turn-on ratio, is a useful quantity that describes the ratio of fluorescence signal to background that can be achieved in an aggregate fluorescence detection experiment. All the dyes underwent an increase in brightness in response to aSyn incorporation $\left(B_{2}>B_{1}\right.$, Figure S7A). All PAP derivatives improved as photon absorbers $\left(\varepsilon_{2}>\varepsilon_{1}\right)$ and increased in $\Phi_{\mathrm{Fl}}$, both of these properties lead to a small increase in $B_{2}$. A lower aSyn aggregate $K_{D}$ compared to the $K_{D}$ for self-association coupled with the increased hydrophobicity of the amyloid binding sites relative to PBS may explain this turn-on response. On the contrary, there was a decrease in $\varepsilon_{2}$ relative to $\varepsilon_{1}$ of all mPAP dyes with the exception of mPAP_1 (ThX). The primary contributor to $B_{2}$ was an increase in $\Phi_{\mathrm{Fl}}$ of $\sim 100 \times$ illustrative of TICT suppression, further suggesting that $\mathrm{N}-5$ methylation is required for the new ThT analogues to exhibit molecularrotor characteristics. ${ }^{45}$ The mPAP derivatives showed significantly larger changes in brightness $(>25 x)$ as a result of aggregate binding compared to their PAP congeners $(>1.1 \times)$. Among the new dyes, mPAP_1 (ThX) showed the largest fold increase in brightness upon aggregate binding of $196 \pm 17.6$, akin to ThT with a turn-on ratio of $200 \pm 15$.2. PAP and mPAP dyes showed directly opposing behaviour when comparing turn-on ratios and heterocyclic ring size (Figure S7B).

It is important to consider the impact that the strength of the interaction between the dyes and $\alpha$ Syn aggregates has on their optical properties. SPR was used to measure the binding affinities of PAP and mPAP derivatives towards aSyn aggregates as this method allows comparison without bias from disparate emission characteristics (Figure S8). Examination of the equilibrium resonance response as a function of dye concentration enabled the calculation of $K_{D}$ values for the different dyes (Table 3 and Table 4). $K_{D}$ values for aSyn aggregates were approximately 10 -fold higher than those obtained via fluorescence, ${ }^{49}$ however the physical interactions in this surface-based method will differ from those in solution. Moreover, fluorescence-based methods are limited to assess binding sites inducing a fluorescence increase, whereas SPR is able to take additional interactions into account. mPAP_5 and ThT showed the same $K_{D}$ value $\left(K_{D}(T h T)=79.4 \pm 6.1 \mu \mathrm{M}, K_{D}(\right.$ mPAP_5 $)=$ $72.3 \pm 6.68 \mu \mathrm{M})$ suggesting that the dye-amyloid interaction is tolerant against the benzothiazole methoxy substituent, further implying that the poorer photophysical properties of mPAP_5 compared to ThT do not originate from weaker binding. All PAP derivatives outperformed ThT as well as their corresponding mPAP partners by more than an order of magnitude, which was in agreement with the literature. ${ }^{35,39,50}$ 
Table 4. Table of photophysical and binding properties of the mPAP dyes and ThT obtained from bulk UV-vis absorption, excitation, fluorescence and SPR measurements of the dyes in the presence of $2 \mu \mathrm{M}$ aSyn aggregates (denoted by subscript 2).Determined properties include wavelengths of maximum absorption ( $\left.\lambda_{\text {abs2 }}\right)$, excitation $\left(\lambda_{\mathrm{ex} 2}\right)$ and fluorescence emission $\left(\lambda_{\mathrm{em} 2}\right)$; Stokes shift $\left(\lambda_{\mathrm{em} 2}-\lambda_{\mathrm{abs} 2}\right)$; molar extinction coefficient $\left(\varepsilon_{2}\right)$; fluorescence quantum yield $\left(\Phi_{\mathrm{FI} 2}\right)$; fluorescence lifetime $\left(\mathrm{T}_{\mathrm{f} \mid 2}\right)$; brightness $\left(\mathrm{B}_{2}\right.$, equal to $\left.\varepsilon_{2} \times \Phi_{\mathrm{FI} 2}\right)$ and dissociation constant $\left(\mathrm{K}_{\mathrm{D}}\right)$.

\begin{tabular}{|c|c|c|c|c|c|c|c|c|c|c|c|}
\hline Dye & $\mathbf{R}$ group & $\begin{array}{l}\lambda_{\text {abs2 }} \\
(\mathrm{nm})\end{array}$ & $\begin{array}{l}\lambda_{\text {ex1 }} \\
(n m)\end{array}$ & $\begin{array}{l}\lambda_{\text {em2 }} \\
(\mathrm{nm})\end{array}$ & $\begin{array}{l}\lambda_{\text {em2- }} \\
\lambda_{\text {abs2 }} \\
(n m)\end{array}$ & $\begin{array}{c}\varepsilon_{2} \\
\left(\mathrm{M}^{-1} \mathrm{~cm}^{-1}\right) \\
/ 10^{3}\end{array}$ & $\Phi_{\mathrm{Fl} 2}$ & $\begin{array}{l}\text { Tfl2 } \\
\text { (ns) }\end{array}$ & $\begin{array}{c}\mathrm{B}_{2} \\
\left(\mathrm{M}^{-1} \mathrm{~cm}^{-1}\right)\end{array}$ & $\frac{\mathrm{B}_{2}^{\mathrm{mPAP}}}{\mathrm{B}_{2}^{\mathrm{ThT}}}$ & $\begin{array}{c}K_{D} \\
(\mu M)\end{array}$ \\
\hline ThT & & 414 & 447 & 483 & 69.0 & 29.52 & 0.24 & 0.14 & 7084.8 & 1.00 & 79.4 \\
\hline $\begin{array}{c}\text { mPAP_1 } \\
(\text { ThX) }\end{array}$ & & 421 & 452 & 490 & 69 & 39.99 & 0.81 & 0.06 & 32388.6 & 4.57 & 38.1 \\
\hline mPAP_2 & & 404 & 436 & 493 & 89 & 15.90 & 0.15 & 0.29 & 2385.0 & 0.34 & 118.3 \\
\hline mPAP_3 & & 424 & 451 & 495 & 71 & 25.34 & 0.61 & --- & 15459.0 & 2.18 & 47.5 \\
\hline mPAP_4 & $-N$ & 432 & $333 / 433$ & 492 & 66 & 20.16 & 0.69 & 0.23 & 13908.0 & 1.96 & 64.2 \\
\hline mPAP_5 & & 420 & 450 & 483 & 63 & 15.45 & 0.26 & 0.23 & 4017.9 & 0.57 & 72.3 \\
\hline mPAP_6 & & 382 & 414 & 506 & 124 & 9.16 & 0.58 & 0.36 & 5311.95 & 0.75 & 78.7 \\
\hline
\end{tabular}

Intensive study of the probe responses to different environments will yield more complete insights about biomolecules. The heterogeneity of aggregate mixtures, synthetic and pathological, enforces the need for them to be studied at high resolution.

The photophysical properties of ThT (large Stokes shift, low $B_{1}$, high $B_{2}$ ) coupled with sensitive instrumentation make it a useful tool to observe amyloid with single-aggregate resolution. ${ }^{20,24,26,51}$ Fluorescence emission of three PAP (PAP_1, PAP_2 and PAP_5) and three mPAP (mPAP_1, mPAP_2 and mPAP_5) derivatives along-side ThT were used to observe single, surface adsorbed $\alpha$ Syn aggregates. These particular dyes were chosen as an interesting comparison between bulk and high-resolution fluorescence properties. The bulk data showed that mPAP_1 and mPAP_2 were the best and worst performing dyes respectively in terms of $B_{2}$ and $K_{D}$, mPAP_ 5 is most closely structurally related to ThT.

In this single-aggregate imaging regime, the dyes were excited with $405 \mathrm{~nm}$ light in a total internal reflection fluorescence (TIRF) geometry and fluorescence emission was collected at 
a peak wavelength of either $434 \mathrm{~nm}$ (PAP) or $480 \mathrm{~nm}$ (mPAP and ThT) (Figure 3A). The images show the emission of the dyes bound to late-stage (>96 hours) recombinant aggregates of aSyn (Figure 3Bi-vii).

A)

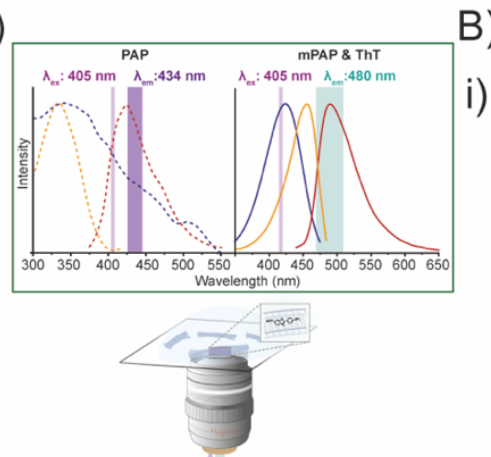

ii)

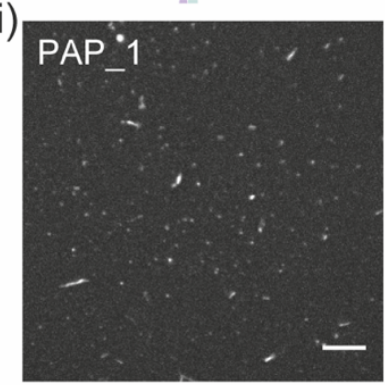

iv)

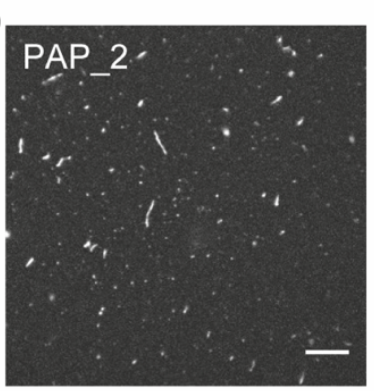

vi)

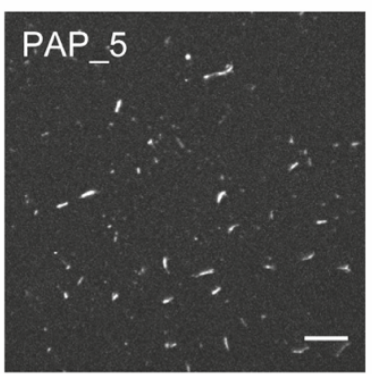

B)

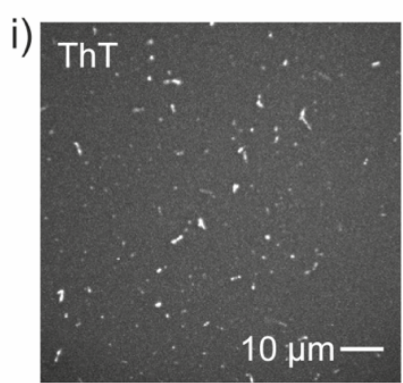

iii)

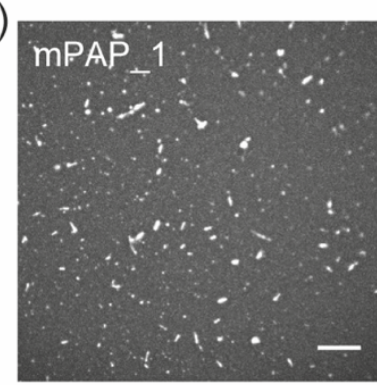

v)

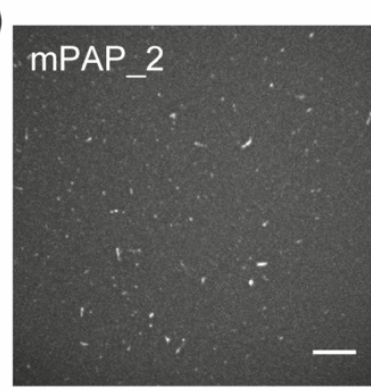

vii)

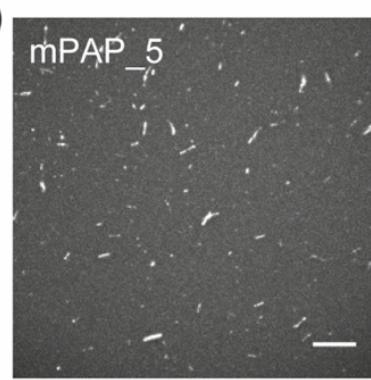

C)

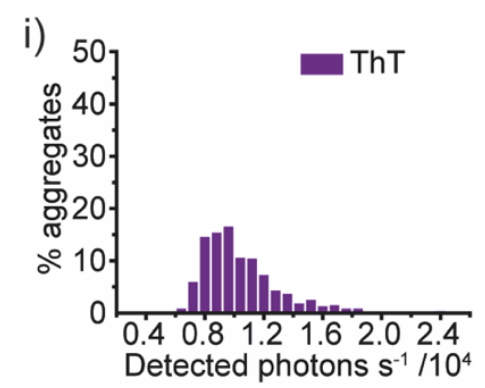

ii)

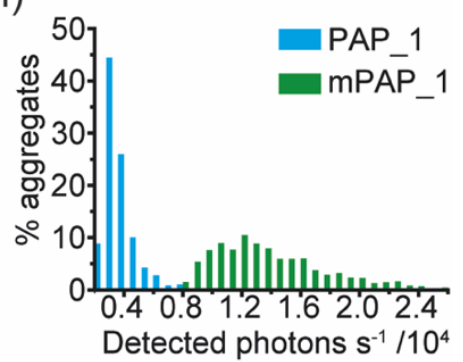

iii)
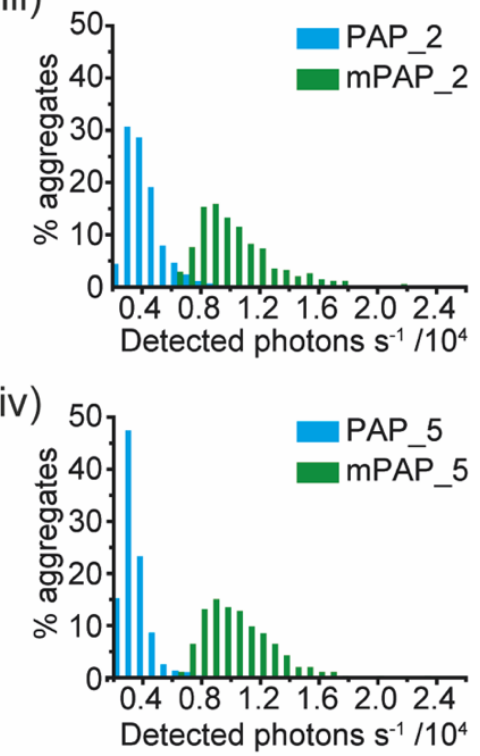

Figure 3. A) Schematic of single-aggregate TIRF imaging experiment, all the dyes were excited with $405 \mathrm{~nm}$ laser light, the midpoint wavelengths for emission collection of the PAP and mPAP dyes were $434 \mathrm{~nm}$ and 480 $\mathrm{nm}$ respectively. The example spectra for PAP, mPAP and ThT include absorption (blue), excitation (orange) and emission (red). B) Single-aggregate TIRF images of $5 \mu \mathrm{M}$ i) ThT, ii) PAP_1, iii) mPAP_1, iv) PAP_2, v) mPAP_2, vi) PAP_5, vii) mPAP_5 bound to surface adsorbed aSyn aggregates (>96 hours). C) Histograms illustrating the number of detected photons/s from i) ThT ( $\mu=9481 \pm 180$ photons/s), ii) PAP_1 ( $\mu=3412 \pm 58$ photons/s) and mPAP_1 ( $\mu=12384 \pm 3437$ photons/s), iii) PAP_2 $(\mu=3838 \pm 91$ photons/s) and mPAP_2 $(\mu=9229 \pm 188$ photons $/ \mathrm{s})$ iv) PAP_ $5(\mu=3303 \pm 58$ photons $/ \mathrm{s})$ and mPAP_ $5(\mu=9731 \pm 215$ photons $/ \mathrm{s}) . \mathrm{N} \geq 800$ aSyn aggregates from 3 cover-slides. 
Despite low $\Phi_{\mathrm{Fl} 2}$ values $(<0.1)$, single aSyn aggregates were visualised with PAP dyes. Additionally, the dyes were excited with $405 \mathrm{~nm}$ light, red-shifted relative to their $\lambda_{\text {ex22. }}$ ThT and the mPAP dyes displayed minimal photobleaching, at worst decaying to $70 \%$ of their maximum fluorescence intensity during the $10 \mathrm{~s}$ acquisition, due to rapid exchange of molecules compared to the detector integration time (Figure S9A,B). ${ }^{24}$ The PAP derivatives (Figure $\mathrm{S9C}$ ) showed significantly greater photobleaching rates, decaying to approximately $50 \%$ of their initial intensity. These observations can be ascribed to the lower $K_{D}$ of the PAP dyes towards aSyn aggregates thus longer binding times, increasing the probability of dye photobleaching.

The single-aggregate level brightness was characterised by extracting the mean number of photons detected/s ( $N_{\text {det }}$ ) across numerous $(\geq 800)$ single aSyn aggregates for each dye during the $10 \mathrm{~s}$ acquisition time (Figure $3 \mathrm{Ci}$-iv). $\mathrm{N}_{\text {det }}$ from ThT was 9481 photons/s, which agrees well previous results. ${ }^{24}$ mPAP_5 and mPAP_2 emitted a similar number of photons to ThT, $\mathrm{N}_{\text {det }}=9731$ and 9229 photons/s respectively, despite $\mathrm{B}_{2}$ of mPAP_2 being $70 \%$ lower than ThT. The photon counts produced by PAP derivatives were approximately a third of those from their methylated counterparts. The $N_{\text {det }}$ from PAP_1, PAP_2 and PAP_5 were 3412,3838 and 3303 photons/s respectively. As well as having the highest $\Phi_{\mathrm{F} 12}$ of all the dyes at the bulk level, $\mathrm{N}_{\text {det }}$ was also higher for mPAP_1 (ThX) (12384 photons/s). The photon distribution of mPAP_1 (ThX) was much broader than ThT and other PAP dyes with a FWHM of 8200 photons/s.

ThT and mPAP_1 (ThX) have previously been demonstrated as probes for single-molecule localisation microscopy (SMLM) exploiting the transient nature of their binding to amyloid proteins and their low solution $\Phi_{\mathrm{FI}}$ in a method termed transient amyloid binding (TAB). ${ }^{49,52}$ It is important to note that achieving TAB requires off-resonance excitation and emission collection that is redshifted relative to single-aggregate imaging. Excitation was achieved at $488 \mathrm{~nm}$ and peak emission was collected at $587 \mathrm{~nm}$ (Figure 4A). Other mPAP derivatives, mPAP_2, mPAP_5 and mPAP_6 also demonstrated capabilities for TAB, isolated molecules of mPAP dyes binding to aSyn fibrils (Figure S10) were obtained over 10,000 frames (200 s, Movie S1) and localised to generate super-resolved images (Figure 4B-F). Despite disparities in bulk and single-aggregate level brightness and binding affinity, all four mPAP dyes and ThT showed similar localisation precisions of $\sim 16 \mathrm{~nm}$ (Figure S11), suggesting the emit similar numbers of photons in this regime. This suggests that the population of molecules detected in TAB experiments appear to be photophysically distinct from the mean of the ensemble. 

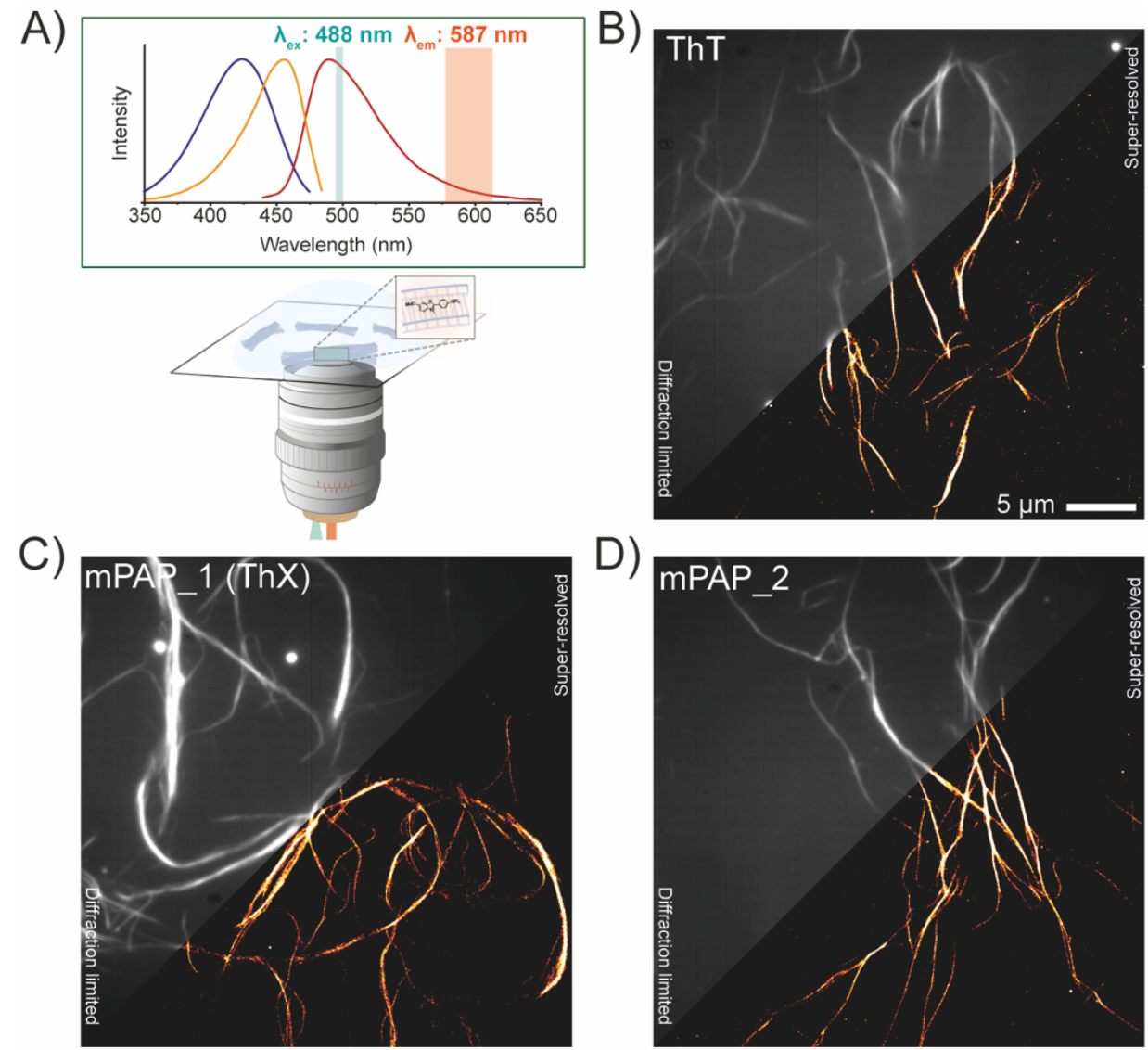

D)

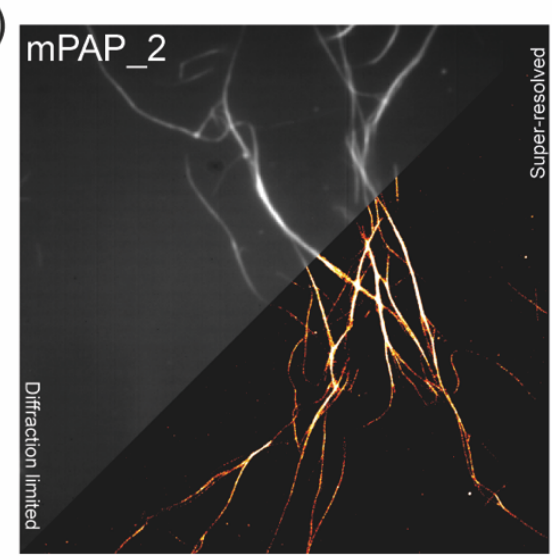

E)

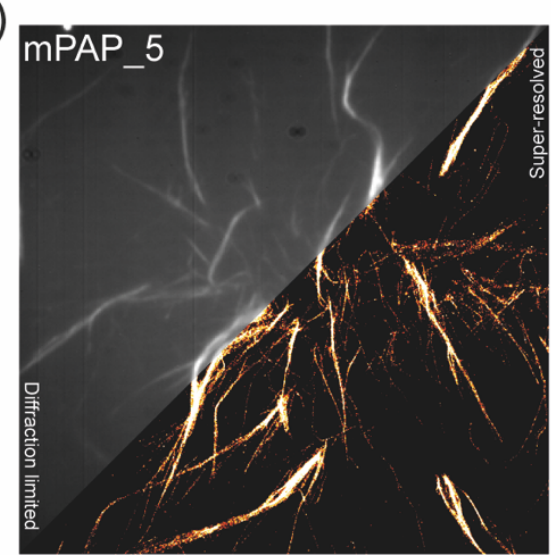

F)

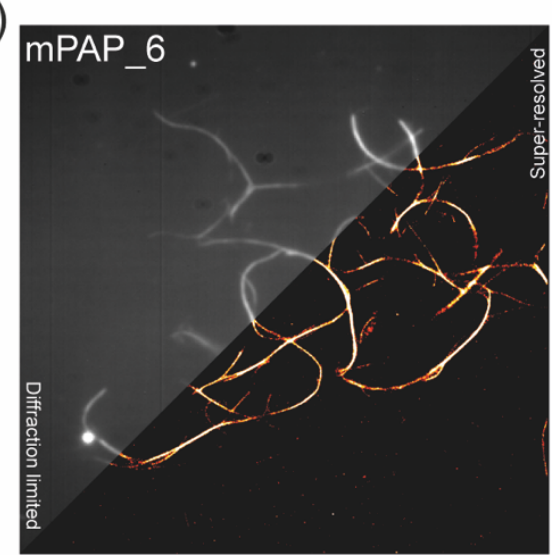

Figure 4. A) Schematic of $T A B$ experiment, all the dyes were excited with $488 \mathrm{~nm}$ laser light, the midpoint wavelength for emission collection was $587 \mathrm{~nm}$. The example spectra include absorption (blue), excitation (orange) and emission (red). Diffraction-limited and super-resolved images of aSyn fibrils (>96 hours) obtained by super-localising spatially isolated molecules of B) ThT, C) mPAP_1 (ThX), D) mPAP_2, E) mPAP_5 and F) mPAP_6 transiently binding to surface adsorbed aSyn fibrils. All images are the same scale.

Temporal grouping of localisations revealed a $\sim 5 \%$ probability of a TAB event across most of the aggregate area (Figure S12), this is typical in order to maintain a spatial isolation of individual emitters. Across the aggregation sample, mPAP_1 (ThX), mPAP_2 and mPAP_6 have regions that showed high activity 'hot spots' ( $\geq 30 \%$, Figure S12 B, C, E). Conversely 
ThT and mPAP_5, which differ only in the benzothiazolium substituent, did not show the same regions of high activity (Figure S12 A, D).

In a steady-state of collisional flux of probes with the aggregate surface, the 'fluorescence off-rate' is a combination of the dissociation constant with the photobleaching rate. Assuming complete dissociation of the probe from a binding site, the probability of additional binding should be constant. This was explored through the metric of total binding site accessibility which describes the length of the acquisition time that a site is available for binding during the course of an imaging experiment (Figure S13). The majority of the aggregate surface was available for TAB throughout the acquisition time (200 s), consistent with a steady-state model. However, some aggregates showed lower accessibility times and heterogeneity within single-aggregates, implying accumulation of probes in these regions. This was again most prominent for ThT and MPAP_5 in which large amounts of the aggregate area showed low and heterogeneous accessibility times (Figure S13A, D), $9.0 \%$ of binding sites were accessible for $<10 \mathrm{~s}$, whereas for mPAP_1, mPAP_2 and mPAP_6, this was only true for $4.0,5.5$ and $6 \%$ of sites respectively. Taken together, these data all support the idea that on the same sample, the different structural variants of the mPAP dyes give rise to distinct kinetic behaviours at the single-molecule level, which could be used to probe structural heterogeneity of amyloid.

This study has explored the relationship between structural modifications and photophysical functions by a systematic comparison of the bulk, single-aggregate and single-molecule level properties of a novel catalogue of ThT-inspired dyes, all of which demonstrated a photophysical response to aSyn aggregate binding. In PBS, the PAP dyes had low $\mathrm{B}_{1}$ resulting from low $\varepsilon$ and $\Phi_{\mathrm{Fl}}$, most likely caused by hydrophobic interactions between dye molecules, lowering the dissolved concentration and increasing the rate of non-radiative decay via quenching. mPAP dyes also had low $\mathrm{B}_{1}$ resulting from poor $\Phi_{\mathrm{Fl} 1}$ due to nonradiative relaxation via a TICT state. Both dye classes exhibited a turn-on in response to aSyn aggregate binding $\left(B_{2}>B_{1}\right)$, the PAP dyes increased in both $\varepsilon$ and $\Phi_{\mathrm{Fl}}$ whereas the mPAP dyes generally increased only in $\Phi_{\mathrm{Fl}}$, suggesting that the increase may be attributed to different mechanisms. In the case of the PAP dyes, the high affinity for amyloid and increased hydrophobicity of the binding environment may be the dominant contributor to the fluorescence turn-on, while suppression of TICT resulting from conformational restriction likely drives the fluorescence turn-on of the mPAP dyes. The PAP and mPAP dyes were able to be applied to image single aSyn aggregates, with the mPAP dyes showing comparable photon counts to ThT. Furthermore, the mPAP derivatives were utilised in a TAB mode to generate super-resolved images of $\alpha$ Syn aggregates, all achieving similar 
localisation precisions of $16 \mathrm{~nm}$, despite differing bulk and single-aggregate level brightness. The exact photophysical nature of this state used for TAB imaging remains unclear; however given that: 1) this behaviour has been observed previously in benzothiazolium derivatives, ${ }^{49,52} 2$ ) the distributions of detected photons at the single-molecule level is broadly similar across all mPAP dyes, (Figure S11) and 3) there is a $\sim 13$ fold differences in the bulk brightness. It can be speculated that the probes are probably not evaluating an ergodic state of the ensemble, but an alternative photophysical state. These results provide insight into how changes of chemical structure affect the photophysical properties of arylbenzothiazoles for amyloid aggregate detection and can be used to further develop new probes for different applications within this context. The $N-5$ methylation is key to achieve high contrast, however, each of the classes of probes responded in a photophysically distinct manner to amyloid incorporation. The potential of these dyes to study independent binding sites and aggregate types at single-aggregate resolution should be further explored.

\section{Supporting Information}

Included within the Supporting Information (PDF); all experimental methods, chemical characterisation, further bulk photophysical characterisations, fluorescence lifetime decay curves, SPR response curves, further single-aggregate imaging and TAB characterisation, supporting movie S1 (raw TAB imaging data). NMR spectra of the PAP and mPAP dyes can be found in the appendix of the Supporting Information.

\section{Acknowledgements}

We thank the Royal Society for the University Research Fellowship of S.F.L. (UF120277). This work was funded in part by the Michael J Fox Foundation and the National Institutes of Health under award number R01GM121573 (awarded to T.N.S.). We thank the EPSRC for the DTA and Doctoral Prize of L.M.N. and for the IAA Follow-on-fund (awarded to S.F.L.). We thank Ewa Klimont and Swapan Preet for a-synuclein protein expression and purification.

\section{References}

(1) Ueda, K.; Fukushima, H.; Masliah, E.; Xia, Y.; Iwai, A.; Yoshimoto, M.; Otero, D. A.; Kondo, J.; Ihara, Y.; Saitoh, T. Molecular Cloning of CDNA Encoding an Unrecognized Component of Amyloid in Alzheimer Disease. Proc. Natl. Acad. Sci. 1993, 90 (23), 11282-11286. https://doi.org/10.1073/pnas.90.23.11282.

(2) Spillantini, M. G.; Schmidt, M. L.; Lee, V. M. Y.; Trojanowski, J. Q.; Jakes, R.; Goedert, M. a-Synuclein in Lewy Bodies. Nature 1997, 388 (6645), 839-840. https://doi.org/10.1038/42166. 
(3) Soto, C. Unfolding the Role of Protein Misfolding in Neurodegenerative Diseases. Nat. Rev. Neurosci. 2003, 4 (1), 49-60. https://doi.org/10.1038/nrn1007.

(4) Vidal, R.; Ghetti, B. Characterization of Amyloid Deposits in Neurodegenerative Diseases. Methods Mol. Biol. 2011, 793, 241-258. https://doi.org/10.1007/978-161779-328-8_16.

(5) Klunk, W. E.; Pettegrew, J. W.; Abraham, D. J. Quantitative Evaluation of Congo Red Binding to Amyloid-like Proteins with a Beta-Pleated Sheet Conformation. J. Histochem. Cytochem. 1989. https://doi.org/10.1177/37.8.2666510.

(6) Åslund, A.; Sigurdson, C. J.; Klingstedt, T.; Grathwohl, S.; Bolmont, T.; Dickstein, D. L.; Glimsdal, E.; Prokop, S.; Lindgren, M.; Konradsson, P.; et al. Novel Pentameric Thiophene Derivatives for in Vitro and in Vivo Optical Imaging of a Plethora of Protein Aggregates in Cerebral Amyloidoses. ACS Chem. Biol. 2009, 4 (8), 673-684. https://doi.org/10.1021/cb900112v.

(7) Lindgren, M.; Sörgjerd, K.; Hammarström, P. Detection and Characterization of Aggregates, Prefibrillar Amyloidogenic Oligomers, and Protofibrils Using Fluorescence Spectroscopy. Biophys. J. 2005, 88 (6), 4200-4212. https://doi.org/10.1529/biophysj.104.049700.

(8) Sutter, M.; Oliveira, S.; Sanders, N. N.; Lucas, B.; Van Hoek, A.; Hink, M. A.; Visser, A. J. W. G.; De Smedt, S. C.; Hennink, W. E.; Jiskoot, W. Sensitive Spectroscopic Detection of Large and Denatured Protein Aggregates in Solution by Use of the Fluorescent Dye Nile Red. J. Fluoresc. 2007. https://doi.org/10.1007/s10895-0070156-6.

(9) Taylor, C. G.; Meisl, G.; Horrocks, M. H.; Zetterberg, H.; Knowles, T. P. J.; Klenerman, D. Extrinsic Amyloid-Binding Dyes for Detection of Individual Protein Aggregates in Solution. Anal. Chem. 2018, 90 (17), 10385-10393. https://doi.org/10.1021/acs.analchem.8b02226.

(10) Campioni, S.; Mannini, B.; Zampagni, M.; Pensalfini, A.; Parrini, C.; Evangelisti, E.; Relini, A.; Stefani, M.; Dobson, C. M.; Cecchi, C.; et al. A Causative Link between the Structure of Aberrant Protein Oligomers and Their Toxicity. Nat. Chem. Biol. 2010, 6 (2), 140-147. https://doi.org/10.1038/nchembio.283.

(11) Chiti, F.; Dobson, C. M. Amyloid Formation by Globular Proteins under Native Conditions. Nat. Chem. Biol. 2009, 5 (1), 15-22. https://doi.org/10.1038/nchembio.131.

(12) Xing, R.; Yuan, C.; Li, S.; Song, J.; Li, J.; Yan, X. Charge-Induced Secondary Structure Transformation of Amyloid-Derived Dipeptide Assemblies from $\beta$-Sheet to $\alpha$ Helix. Angew. Chemie Int. Ed. 2018, 57 (6), 1537-1542. https://doi.org/10.1002/anie.201710642. 
(13) Hamada, D.; Tanaka, T.; Tartaglia, G. G.; Pawar, A.; Vendruscolo, M.; Kawamura, M.; Tamura, A.; Tanaka, N.; Dobson, C. M. Competition between Folding, Native-State Dimerisation and Amyloid Aggregation in $\beta$-Lactoglobulin. J. Mol. Biol. 2009, 386 (3), 878-890. https://doi.org/10.1016/J.JMB.2008.12.038.

(14) Cremades, N.; Cohen, S. I. A.; Deas, E.; Abramov, A. Y.; Chen, A. Y.; Orte, A.; Sandal, M.; Clarke, R. W.; Dunne, P.; Aprile, F. A.; et al. Direct Observation of the Interconversion of Normal and Toxic Forms of a-Synuclein. Cell 2012, 149 (5), 10481059. https://doi.org/10.1016/j.cell.2012.03.037.

(15) Winner, B.; Jappelli, R.; Maji, S. K.; Desplats, P. A.; Boyer, L.; Aigner, S.; Hetzer, C.; Loher, T.; Vilar, M.; Campioni, S.; et al. In Vivo Demonstration That a-Synuclein Oligomers Are Toxic. Proc. Natl. Acad. Sci. 2011, 108 (10), 4194-4199. https://doi.org/10.1073/pnas.1100976108.

(16) Cohen, S. I. A.; Linse, S.; Luheshi, L. M.; Hellstrand, E.; White, D. A.; Rajah, L.; Otzen, D. E.; Vendruscolo, M.; Dobson, C. M.; Knowles, T. P. J. Proliferation of Amyloid-B42 Aggregates Occurs through a Secondary Nucleation Mechanism. Proc. Natl. Acad. Sci. 2013, 110 (24), 9758-9763. https://doi.org/10.1073/pnas.1218402110.

(17) Seidler, P. M.; Boyer, D. R.; Rodriguez, J. A.; Sawaya, M. R.; Cascio, D.; Murray, K.; Gonen, T.; Eisenberg, D. S. Structure-Based Inhibitors of Tau Aggregation. Nat. Chem. 2017, 10 (2), 170-176. https://doi.org/10.1038/nchem.2889.

(18) Ono, K.; Condron, M. M.; Teplow, D. B. Structure-Neurotoxicity Relationships of Amyloid-Protein Oligomers; 2009; Vol. 106.

(19) Shammas, S. L.; Garcia, G. A.; Kumar, S.; Kjaergaard, M.; Horrocks, M. H.; Shivji, N.; Mandelkow, E.; Knowles, T. P. J.; Mandelkow, E.; Klenerman, D. A Mechanistic Model of Tau Amyloid Aggregation Based on Direct Observation of Oligomers. Nat. Commun. 2015, 6 (1), 7025. https://doi.org/10.1038/ncomms8025.

(20) Varela, J. A.; Rodrigues, M.; De, S.; Flagmeier, P.; Gandhi, S.; Dobson, C. M.; Klenerman, D.; Lee, S. F. Optical Structural Analysis of Individual a-Synuclein Oligomers. Angew. Chemie Int. Ed. 2018, 57 (18), 4886-4890. https://doi.org/10.1002/anie.201710779.

(21) Groenning, M. Binding Mode of Thioflavin T and Other Molecular Probes in the Context of Amyloid Fibrils-Current Status. J. Chem. Biol. 2010, 3 (1), 1-18. https://doi.org/10.1007/s12154-009-0027-5.

(22) Wolfe, L. S.; Calabrese, M. F.; Nath, A.; Blaho, D. V.; Miranker, A. D.; Xiong, Y. Protein-Induced Photophysical Changes to the Amyloid Indicator Dye Thioflavin T. Proc. Natl. Acad. Sci. 2010, 107 (39), 16863-16868. https://doi.org/10.1073/pnas.1002867107. 
(23) Krebs, M. R. H.; Bromley, E. H. C.; Donald, A. M. The Binding of Thioflavin-T to Amyloid Fibrils: Localisation and Implications. J. Struct. Biol. 2005, 149 (1), 30-37. https://doi.org/10.1016/j.jsb.2004.08.002.

(24) Horrocks, M. H.; Lee, S. F.; Gandhi, S.; Magdalinou, N. K.; Chen, S. W.; Devine, M. J.; Tosatto, L.; Kjaergaard, M.; Beckwith, J. S.; Zetterberg, H.; et al. Single-Molecule Imaging of Individual Amyloid Protein Aggregates in Human Biofluids. ACS Chem. Neurosci. 2016, 7 (3), 399-406. https://doi.org/10.1021/acschemneuro.5b00324.

(25) Lee, J. E.; Sang, J. C.; Rodrigues, M.; Carr, A. R.; Horrocks, M. H.; De, S.; Bongiovanni, M. N.; Flagmeier, P.; Dobson, C. M.; Wales, D. J.; et al. Mapping Surface Hydrophobicity of a-Synuclein Oligomers at the Nanoscale. Nano Lett. 2018, 18 (12), 7494-7501. https://doi.org/10.1021/acs.nanolett.8b02916.

(26) Ban, T.; Hoshino, M.; Takahashi, S.; Hamada, D.; Hasegawa, K.; Naiki, H.; Goto, Y. Direct Observation of $A \beta$ Amyloid Fibril Growth and Inhibition. J. Mol. Biol. 2004, 344 (3), 757-767. https://doi.org/10.1016/j.jmb.2004.09.078.

(27) Stsiapura, V. I.; Maskevich, A. A.; Kuzmitsky, V. A.; Uversky, V. N.; Kuznetsova, I. M.; Turoverov, K. K. Thioflavin T as a Molecular Rotor: Fluorescent Properties of Thioflavin T in Solvents with Different Viscosity. J. Phys. Chem. B 2008, 112 (49), 15893-15902. https://doi.org/10.1021/jp805822c.

(28) Freire, S.; De Araujo, M. H.; Al-Soufi, W.; Novo, M. Photophysical Study of Thioflavin T as Fluorescence Marker of Amyloid Fibrils. Dye. Pigment. 2014, 110, 97-105. https://doi.org/10.1016/j.dyepig.2014.05.004.

(29) Naik, L. R.; Naik, A. B.; Pal, H. Steady-State and Time-Resolved Emission Studies of Thioflavin-T. J. Photochem. Photobiol. A Chem. 2009, 204 (2-3), 161-167. https://doi.org/10.1016/j.jphotochem.2009.03.016.

(30) Voropai, E. S.; Samtsov, M. P.; Kaplevskii, K. N.; Maskevich, A. A.; Stepuro, V. I.; Povarova, O. I.; Kuznetsova, I. M.; Turoverov, K. K.; Fink, A. L.; Uverskii, V. N. Spectral Properties of Thioflavin T and Its Complexes with Amyloid Fibrils. J. Appl. Spectrosc. 2003, 70 (6), 868-874. https://doi.org/10.1023/B:JAPS.0000016303.37573.7e.

(31) Stsiapura, V. I.; Maskevich, A. A.; Kuzmitsky, V. A.; Turoverov, K. K.; Kuznetsova, I. M. Computational Study of Thioflavin T Torsional Relaxation in the Excited State. J. Phys. Chem. A 2007, 111 (22), 4829-4835. https://doi.org/10.1021/jp070590o.

(32) Stsiapura, V. I.; Kurhuzenkau, S. A.; Kuzmitsky, V. A.; Bouganov, O. V.; Tikhomirov, S. A. Solvent Polarity Effect on Nonradiative Decay Rate of Thioflavin T. J. Phys. Chem. A 2016, 120 (28), 5481-5496. https://doi.org/10.1021/acs.jpca.6b02577.

(33) Stsiapura, V. I.; Maskevich, A. A.; Tikhomirov, S. A.; Buganov, O. V. Charge Transfer Process Determines Ultrafast Excited State Deactivation of Thioflavin T in Low- 
Viscosity Solvents. J. Phys. Chem. A 2010, 114 (32), 8345-8350.

https://doi.org/10.1021/jp105186z.

(34) Vus, K.; Trusova, V.; Gorbenko, G.; Sood, R.; Kinnunen, P. Thioflavin T Derivatives for the Characterization of Insulin and Lysozyme Amyloid Fibrils in Vitro:

Fluorescence and Quantum-Chemical Studies. J. Lumin. 2015, 159, 284-293.

https://doi.org/10.1016/j.jlumin.2014.10.042.

(35) Mathis, C. A.; Wang, Y.; Holt, D. P.; Huang, G. F.; Debnath, M. L.; Klunk, W. E. Synthesis and Evaluation of 11C-Labeled 6-Substituted 2-Arylbenzothiazoles as Amyloid Imaging Agents. J. Med. Chem. 2003, 46 (13), 2740-2754. https://doi.org/10.1021/jm030026b.

(36) Klunk, W. E.; Wang, Y.; Huang, G. feng; Debnath, M. L.; Holt, D. P.; Mathis, C. A. Uncharged Thioflavin-T Derivatives Bind to Amyloid-Beta Protein with High Affinity and Readily Enter the Brain. Life Sci. 2001. https://doi.org/10.1016/S00243205(01)01232-2.

(37) Stsiapura, V. I.; Gogoleva, S. D.; Maskevich, A. A.; Buganov, O. V; Tikhomirov, S. A.; Stepanov, B. I.; Lugovski, A. A.; Baruah, K.; Sarma, B. K. Effect of Substituents on TICT Rate in Thiofavin T-Based Fluorescent Molecular Rotors. Int. J. Nanosci. 2019, 18. https://doi.org/10.1142/S0219581X19400465.

(38) Kitts, C. C.; Vanden Bout, D. A. A Spectroscopic Study of 2-[4'(Dimethylamino)Phenyl]-Benzothiazole Binding to Insulin Amyloid Fibrils. J. Fluoresc. 2010, 20 (4), 881-889. https://doi.org/10.1007/s10895-010-0634-0.

(39) Mora, A. K.; Murudkar, S.; Alamelu, A.; Singh, P. K.; Chattopadhyay, S.; Nath, S. Benzothiazole-Based Neutral Ratiometric Fluorescence Sensor for Amyloid Fibrils. Chem. - A Eur. J. 2016, 22 (46), 16505-16512. https://doi.org/10.1002/chem.201602981.

(40) Wu, C.; Bowers, M. T.; Shea, J.-E. On the Origin of the Stronger Binding of PIB over Thioflavin T to Protofibrils of the Alzheimer Amyloid- $\beta$ Peptide: A Molecular Dynamics Study. Biophys. J. 2011, 100 (5), 1316-1324. https://doi.org/10.1016/j.bpj.2011.01.058.

(41) Lockhart, A.; Ye, L.; Judd, D. B.; Merrittu, A. T.; Lowe, P. N.; Morgenstern, J. L.; Hong, G.; Gee, A. D.; Brown, J. Evidence for the Presence of Three Distinct Binding Sites for the Thioflavin T Class of Alzheimer's Disease PET Imaging Agents on $\beta$ Amyloid Peptide Fibrils. J. Biol. Chem. 2005, 280 (9), 7677-7684. https://doi.org/10.1074/jbc.M412056200.

(42) Klunk, W. E.; Engler, H.; Nordberg, A.; Wang, Y.; Blomqvist, G.; Holt, D. P.; Bergström, M.; Savitcheva, I.; Huang, G. F.; Estrada, S.; et al. Imaging Brain Amyloid in Alzheimer's Disease with Pittsburgh Compound-B. Ann. Neurol. 2004, 55 (3), 306- 
319. https://doi.org/10.1002/ana.20009.

(43) Yang, P.; Wang, R.; Wu, H.; Du, Z.; Fu, Y. Pd-Catalyzed C-H Arylation of Benzothiazoles with Diaryliodonium Salt: One-Pot Synthesis of 2-Arylbenzothiazoles. Asian J. Org. Chem. 2017, 6 (2), 184-188. https://doi.org/10.1002/ajoc.201600514.

(44) Vus, K.; Trusova, V.; Gorbenko, G.; Sood, R.; Kinnunen, P. Thioflavin T Derivatives for the Characterization of Insulin and Lysozyme Amyloid Fibrils in Vitro:

Fluorescence and Quantum-Chemical Studies. J. Lumin. 2015, 159, 284-293. https://doi.org/10.1016/j.jlumin.2014.10.042.

(45) Gogoleva, S. D.; Kalganova, E. V.; Maskevich, A. A.; Lugovski, A. A.; Kuzmitsky, V. A.; Goswami, M.; Buganov, O. V.; Tikhomirov, S. A.; Stsiapura, V. I. Neutral Derivatives of Thioflavin T Do Not Exhibit Viscosity-Dependent Fluorescence. J. Photochem. Photobiol. A Chem. 2018, 358, 76-91. https://doi.org/10.1016/j.jphotochem.2018.03.003.

(46) Maskevich, A. A.; Stsiapura, V. I.; Kuzmitsky, V. A.; Kuznetsova, I. M.; Povarova, O. I.; Uversky, V. N.; Turoverov, K. K. Spectral Properties of Thioflavin T in Solvents with Different Dielectric Properties and in a Fibril-Incorporated Form. J. Proteome Res. 2007, 6 (4), 1392-1401. https://doi.org/10.1021/pr0605567.

(47) Lord, S. J.; Lu, Z.; Wang, H.; Willets, K. A.; Schuck, P. J.; Lee, H. D.; Nishimura, S. Y.; Twieg, R. J.; Moerner, W. E. Photophysical Properties of Acene DCDHF Fluorophores: Long-Wavelength Single-Molecule Emitters Designed for Cellular Imaging. J. Phys. Chem. A 2007, 111 (37), 8934-8941.

https://doi.org/10.1021/jp0712598.

(48) Amdursky, N.; Erez, Y.; Huppert, D. Molecular Rotors: What Lies behind the High Sensitivity of the Thioflavin-T Fluorescent Marker. Acc. Chem. Res. 2012, 45 (9), 1548-1557. https://doi.org/10.1021/ar300053p.

(49) Needham, L.-M.; Weber, J.; Varela, J. A.; Fyfe, J. W. B.; Do, D. T.; Xu, C. K.; Tutton, L.; Cliffe, R.; Keenlyside, B.; Klenerman, D.; et al. ThX - a next-Generation Probe for the Early Detection of Amyloid Aggregates. Chem. Sci. 2020. https://doi.org/10.1039/C9SC04730A.

(50) Wu, C.; Bowers, M. T.; Shea, J. E. On the Origin of the Stronger Binding of PIB over Thioflavin T to Protofibrils of the Alzheimer Amyloid- $\beta$ Peptide: A Molecular Dynamics Study. Biophys. J. 2011, 100 (5), 1316-1324.

https://doi.org/10.1016/j.bpj.2011.01.058.

(51) Ban, T.; Hamada, D.; Hasegawall, K.; Naiki, H.; Goto, Y. Direct Observation of Amyloid Fibril Growth Monitored by Thioflavin T Fluorescence. J. Biol. Chem. 2003, 278 (19), 16462-16465. https://doi.org/10.1074/jbc.C300049200.

(52) Spehar, K.; Ding, T.; Sun, Y.; Kedia, N.; Lu, J.; Nahass, G. R.; Lew, M. D.; Bieschke, 
J. Super-Resolution Imaging of Amyloid Structures over Extended Times by Using Transient Binding of Single Thioflavin T Molecules. ChemBioChem 2018, 19 (18), 1944-1948. https://doi.org/10.1002/cbic.201800352. 